\title{
Italian Survey for the Evaluation of the Effects of Coronavirus Disease 2019 (COVID-19) Pandemic on Alopecia Areata Recurrence
}

Fabio Rinaldi (D) - Anna Trink - Giammaria Giuliani $\cdot$ Daniela Pinto

Received: November 20, 2020 / Published online: February 12, 2021

(C) The Author(s) 2021

\begin{abstract}
Introduction: The inflammation storm involved in coronavirus disease 2019 (COVID19) infection and worsening and the psychological stress derived from current quarantine conditions can affect the course of many skin and scalp conditions. This study examined the possible effects of COVID-19 on alopecia areata (AA) relapse in patients suffering from these scalp conditions during the pandemic.

Methods: The study was carried out in the form of an observational cross-sectional type using a questionnaire sent by mail to a cohort of patients affected by AA during the pandemic from March 2020 to October 2020.

Results: During the pandemic, AA relapse was reported in $42.5 \%$ of the participants who also declared COVID-19 infection, confirmed by nasopharyngeal swab or hematological analysis. The relapse was reported about 2 months later COVID-19 infection (median of 2.14 months) and $74.0 \%$ of these participants continue to experience AA symptoms when the survey was proposed. Only $12.5 \%$ of participants reported AA relapse in the absence of COVID-19 infection.
\end{abstract}

F. Rinaldi $(\bowtie)$ - A. Trink · G. Giuliani · D. Pinto International Hair Research Foundation (IHRF), Milan, Italy

e-mail: fabio.rinaldi@studiorinaldi.com
Conclusions: The present study reported a significant relapse in patients suffering from AA and infected by COVID-19. This phenomenon could be attributed to the inflammation storm typical of COVID-19 infection and the psychological stress derived from quarantine conditions.

Keywords: AA; Alopecia areata; COVID-19; Inflammation; Psychological stress

\section{Key Summary Point}

The data in the present study showed a significant relapse in patients suffering from AA and infected by COVID-19. This phenomenon could be attributed to the inflammation storm typical of COVID-19 infection and to the psychological stress derived from quarantine conditions

\section{DIGITAL FEATURES}

This article is published with digital features, including a summary slide, to facilitate understanding of the article. To view digital features for this article go to https://doi.org/10.6084/ m9.figshare.13650644. 


\section{INTRODUCTION}

Coronavirus disease 2019 (COVID-19) is affecting individuals of all ages worldwide. Reported for the first time in people exposed to a seafood market in Wuhan City, China in December 2019 , it is caused by severe acute respiratory syndrome coronavirus 2 (SARS-CoV-2).

Because of its continuous and growing diffusion, COVID-19 incidence is difficult to estimate. Data updated in November 2020 reported a worldwide incidence of 53.7 million confirmed cases and 1.3 million deaths [1].

Also in Italy, especially since 10 October 2020 , there has been a further strong increase in cases, which brings the cumulative incidence to $1,183,957$ total cases [2], with a median age of 48 years with a distribution between male and female of $49.1 \%$ and $50.9 \%$, respectively.

New concerns emerged with reports on hair loss in subjects with COVID-19 as reported in publicly available data and opinions from dermatologists all around the world, including Italy. This topic was discussed in November 2020 at the 94th SIDEMAST Congress in Italy with an estimation of the incidence of hair loss in subjects with COVID-19 of about 30\%. In particular, in about $90 \%$ of cases, hair loss is reported to occur after 2 or 3 months of healing, mainly in the form of acute telogen effluvium [3].

Our studies on alopecia areata (AA) led us to investigate an association between AA recurrence and COVID-19 pathogenesis in a sample of patients from all over Italy in the period from March to October 2020. AA is a chronic autoimmune inflammatory disease characterized by sudden hair loss typically with a course of spontaneous remission and exacerbation $[4,5]$. The loss of immune privilege is reported as the main trigger of AA [6], but also inflammation and acute or chronic psycho-emotional stress have been reported as causative agents of AA as contributors to its progress $[7,8]$. Indeed, inflammatory skin diseases, including AA, can be exacerbated by psychological stress via stimulation of the neuroendocrine system [9]. At the same time, it could also be hypothesized that the "storm" of inflammation experienced by patients with COVID-19 could lead to an increase of immune molecules linked to the AA condition.

This study examined the possible effects of COVID-19 on AA recurrence in subjects who had experienced the virus both by hospitalization and quarantine.

\section{METHODS}

\section{Participants and Questionnaire}

The study was carried out in the form of an observational cross-sectional type using a questionnaire sent by mail to the participants. They were enrolled based on a previous well-known history of AA, and demographics such as age and gender were recorded. Inclusion criteria were a history of AA and positivity to COVID-19 infection ascertained via nasopharyngeal swabs. After they were asked whether they had these complaints, those who positively answered were asked for the gravity of symptoms, therapies to which they have been subjected, and postpandemic AA manifestations. The survey was sent by mail and includes a total of eight questions (Fig. 1). Demographic information was obtained from the patient's medical history. We also asked the patient to send a digital photograph of their scalp condition to evaluate and confirm AA relapse.

Once collected, questions were reviewed by two dermatologists and a biostatistics specialist. All procedures performed in studies involving human participants were in accordance with the ethical standards of the institutional and/or national research committee and with the 1964 Helsinki declaration and its later amendments or comparable ethical standards. No ethics committee approval was required since the study has been conducted in the form of survey on patients without any clinical examinations. Written informed consent was obtained from the patients for the publication of this case report and accompanying images. 
1. Did you contract the Covid-19 virus from March to October 2020?

$\begin{array}{ll}\square & \text { Yes } \\ \square & \text { No }\end{array}$

2. If so, have you ascertained the presence of the virus by means of a nasopharyngeal swab or hematological test?

口 Yes

口 No

3. If so, did you have any significant viremia symptoms?

$\square$ Yes

4. Did you have to undergo some specific therapy?
a Yes
No

5. Have you had a relapse of Alopecia Areata after COVID-19 infection from March to October 2020?

$\square$ Yes

口 No

6. Have you had a relapse of Alopecia Areata after COVID-19 infection from March to October 2020?

$\square$ Yes

Do

7. Do you have still persistence of AA symptoms?

$\square$ Yes

№

8. Please feel free to write any additional comments if you wish

Fig. 1 Patient questionnaire

\section{RESULTS}

A total of 475 patients affected by AA in the last 2 years were contacted about the survey, of whom $82 \%$ completed it. Of the subjects contacted, $15 \%$ of subjects did not answer the mail. The remaining 3\% did not answer the survey correctly. Among these, one subject reported a history of COVID-19 infection but without nasopharyngeal swab or hematological assessment and for this reason was excluded from the enrollment. A flowchart of the respondents to the questionnaire is reported in Fig. 1 and their demographic characteristics are reported in Table 1.

Thirty-four percent of participants responded "Yes" to question 1 ("Did you contract the COVID-19 virus from March to October 2020?") 
Table 1 Demographic characteristics of the respondents

\begin{tabular}{lll}
\hline Features & Subgroups & Values \\
\hline Sex & Male & $353(90.0 \%)$ \\
& Female & $39(10.0 \%)$ \\
Age (years) & $27-61$ & 35 years (median age) \\
\hline
\end{tabular}

(Fig. 3a). Among these, 90\% ascertained the presence of the virus using a nasopharyngeal swab or hematological test (Fig. 3b) and 59\% of them reported significant symptoms of viremia (Fig. 3c). In particular, nine of them $(7.0 \%$ of the total number of affected subjects) were hospitalized and needed intensive therapy care and intubation (Fig. 3d). The remaining 44\% (52.0\% of the total number of affected subjects) were treated with mild antipyretics, cortisone, heparin, and hydroxychloroquine (Fig. 3d). Forty-one percent of affected subjects were treated with antipyretics (Fig. 2d). Most interesting, $44 \%$ of subjects affected by COVID-19 enrolled in this study reported AA relapse (Fig. 3e) about 2 months after COVID-19 infection (median of 2.14 months) and $74 \%$ of them still experienced AA symptoms when the survey was proposed (Fig. 3e).

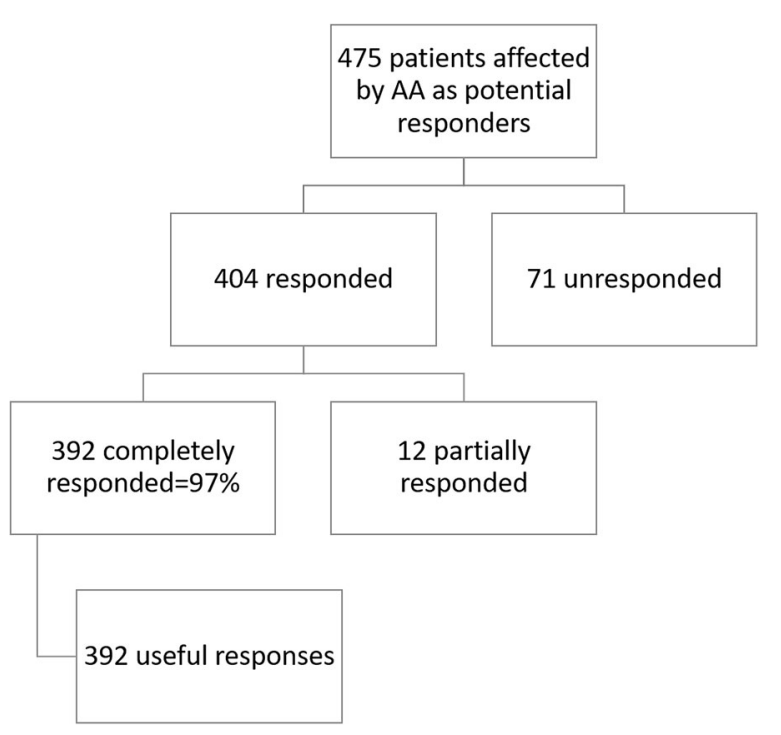

Fig. 2 Flowchart of the respondents to the questionnaire
Only $12 \%$ of COVID-19-negative subjects reported AA relapse (Fig. 3f) and 55\% of these reported the persistence of symptoms (Fig. 3f).

\section{DISCUSSION}

In this study, the incidence of relapse in individuals affected by AA after COVID-19 infection in the period from March to October 2020 was examined through a questionnaire and compared with non-infected subjects. As soon as the COVID-19 pandemic started, scientists began to notice and investigate dermatological manifestations related to COVID-19 infection.

With COVID-19 spreading all around the world from March 2020, evidence both from physicians and patients started to suggest an increase of hair loss after COVID-19 recover. It could be hypothesized that physical and emotional stress experienced during COVID-19 infection could lead to telogen effluvium-like conditions which usually are reported to occur a few months after a stressful event (e.g., emotional stress, surgery, high fever, etc.). Limited published data are available on this topic [10], but much evidence is currently available from public data or reported from clinical experience. However, we could not find any study on AA relapse in subjects affected by this condition during the COVID-19 pandemic in Italy.

Relapse in subjects with AA from an Italian cohort of subjects affected both by AA and COVID-19 was found to statistically increase during the pandemic ( $42.5 \%$ vs $12.5 \%)$. These data are in line with a previous Turkish study from Kutlu et al. [11] in the period from May 2019 to May 2020.

AA is a well-studied autoimmune and chronic inflammatory disease $[4,5]$ in which psycho-emotional stress may also be involved [9].

Stress derived from quarantine conditions such as that deriving from health and economical insecurity could be proposed as a triggering factor of AA relapse and persistence reported in this study. Indeed, stress is reported to have an impact on other skin conditions in which stress is reported to exert a role $[12,13]$. 
A Did you contract the Covid-19 virus from March - October 2020?

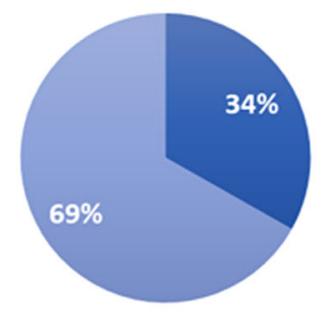

m YES $\equiv$ NO

C If so, did you have any significant viremia symptoms?

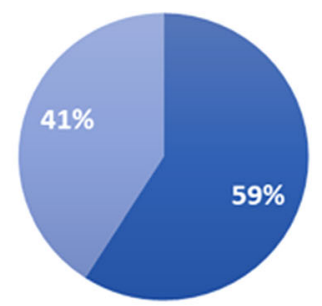

a YES $\equiv N O$

E

Have you had a relapse of Alopecia Areata after COVID-19 infection from March to October 2020?

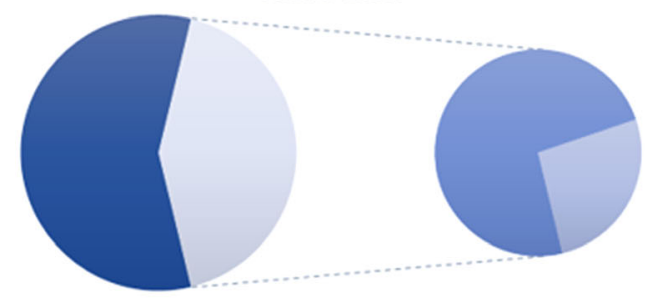

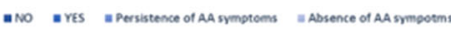

Fig. 3 Survey results regarding the incidence of COVID19 and symptoms as reported by subjects with alopecia areata (AA) who responded to the survey: a COVID-19 virus in the period of March-October 2020, $\mathbf{b}$ assessment of COVID-19 by means of a nasopharyngeal swab or

Most interesting, the generalized inflammation deriving from COVID-19 infection also has to be taken into account, considering the role of inflammation in AA.

Recently, Bulat and collaborators [14] reported an overactivation of $T$ cells in patients with COVID-19, which reflects an increase in the Th17 subset of $\mathrm{CD}^{+}$T cells. This leads to increased production of both interleukin-17 (IL17) and IL-22 cytokines, the main triggers of cytokine release storm (CRS) leading to the
B If so, have you ascertained the presence of the virus by means of a nasopharyngeal swab or hematological test?

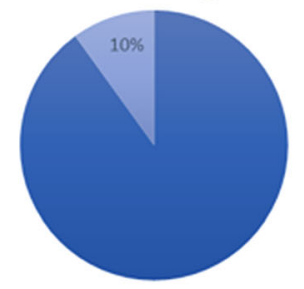

- YES $=$ NO

\section{Did you have to undergo some} specific therapy?

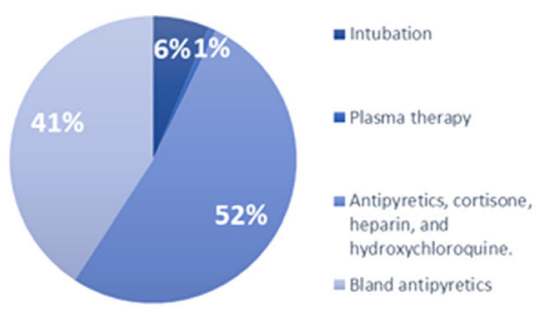

$\mathbf{F}$ Did you have a relapse of AA from March to October 2020?

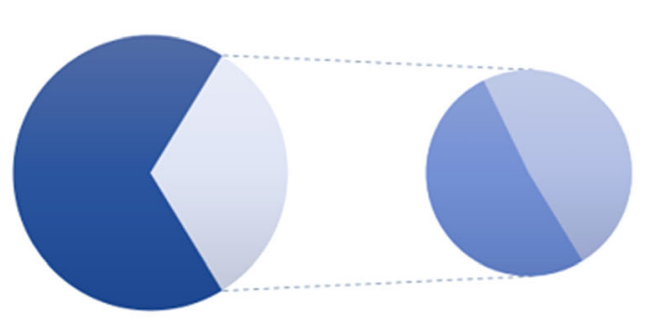

- No - Yes E Persistence of AA symptoms = Absence of AA smmoorms

hematological test, $\mathbf{c}$ significant viremia symptoms, $\mathbf{d}$ specific therapies, e relapse of AA after COVID-19 infection, f relapse of AA in COVID-19-negative subjects

rapid and severe deterioration of the condition of patients with COVID-19 [15]. AA is itself associated with the dysregulation in systemic type 17 and type 2 cytokines, and IL-17 has been proposed as a target for AA treatment [16]. Indeed, IL-17 represents a systemic inflammatory signature of AA and, most interesting, is also reported to contribute to disease-associated psychological morbidity [17]. Increased plasma levels of the type 2 cytokines (IL-33, IL-31, and IL-15) were reported in subjects with AA, in 
addition to type 17 cytokines (IL-17A, IL-21, IL23, and IL-17F) and the levels of these cytokines positively predict depression score [17].

Taken together, this evidence is coherent with the so-called brain-skin axis [18] which clearly explains the strict relationship between psychological triggers and changes in the hair growth cycle.

A limitation of this study is that no clinical investigations were conducted apart from photographic evaluations to assess AA relapse. Additional clinical investigations are currently underway.

\section{CONCLUSION}

The data obtained in our study showed that there is a significant relapse in patients suffering from AA and infected by COVID-19. This phenomenon could be attributed to the inflammation storm typical of COVID-19 infection and to the psychological stress derived from quarantine conditions. Considering that COVID-19 is continuously spreading all around the world, we think that the number of patients could increase gradually in the future.

\section{AKNOWLEDGEMENTS}

We thank the participants of the study.

Funding. The journal's Rapid Service Fee was funded by Giuliani S.p.A. All authors had full access to all of the data in this study and take complete responsibility for the integrity of the data and the accuracy of the data analysis.

Authorship. All named authors meet the International Committee of Medical Journal Editors (ICMJE) criteria for authorship for this manuscript, take responsibility for the integrity of the work as a whole, and have given final approval for the version to be published.

Disclosures. Fabio Rinaldi, Anna Trink, Giammaria Giuliani and Daniela Pinto have nothing to disclose.
Compliance with Ethics Guidelines. All procedures performed in studies involving human participants were in accordance with the ethical standards of the institutional and/or national research committee and with the 1964 Helsinki declaration and its later amendments or comparable ethical standards. No ethics committee approval was required since the study has been conducted in the form of survey on patients without any clinical examinations. Written informed consent was obtained from the patients for the publication of this case report and accompanying images.

Data Availability. The datasets used and/or analyzed during the current study are available from the corresponding author on reasonable request.

Open Access. This article is licensed under a Creative Commons Attribution-NonCommercial 4.0 International License, which permits any non-commercial use, sharing, adaptation, distribution and reproduction in any medium or format, as long as you give appropriate credit to the original author(s) and the source, provide a link to the Creative Commons licence, and indicate if changes were made. The images or other third party material in this article are included in the article's Creative Commons licence, unless indicated otherwise in a credit line to the material. If material is not included in the article's Creative Commons licence and your intended use is not permitted by statutory regulation or exceeds the permitted use, you will need to obtain permission directly from the copyright holder. To view a copy of this licence, visit http://creativecommons.org/licenses/by$\mathrm{nc} / 4.0 /$.

\section{REFERENCES}

1. WHO. Weekly epidemiological update - 17 November 2020. https://www.who.int/publica tions/m/item/weekly-epidemiological-update-17november-2020. 
2. Epidemiology for public health, ISS. COVID-19 integrated surveillance data in Italy. https://www. epicentro.iss.it/en/coronavirus/sars-cov-2-dashboard.

3. Domínguez-Santás M, Haya-Martínez L, FernándezNieto D, Jiménez-Cauhé J, Suárez-Valle A, DíazGuimaraens B. Acute telogen effluvium associated with SARS-CoV-2 infection. Aust J Gen Pract. 2020;26:49.

4. Gilhar A, Kalish RS. Alopecia areata: a tissue specific autoimmune disease of the hairfollicle. Autoimmun Rev. 2006;5(1):64-9.

5. McDonagh AJ, Messenger AG. Alopecia areata. Clin Dermatol. 2001;19(2):141-7.

6. Kang $\mathrm{H}, \mathrm{Wu} \mathrm{WY}$, Lo BK, et al. Hair follicles from alopecia areata patients exhibit alterations in immune privilege-associated gene expression in advance of hair loss. J Invest Dermatol. 2010;130(11):2677-80.

7. Ito T, Kageyama R, Nakazawa S, Honda T. Understanding the significance of cytokines and chemokines in the pathogenesis of alopecia areata. Exp Dermatol. 2020;29(8):726-32.

8. Arı B, Çenesizoğlu E, Denli Y. Psychiatric symptoms in patients with alopecia areata. Turkderm-Arch Turkish Dermatol Venerol. 2011;45:203-5.

9. Willemsen R, Roseeuw D, Vanderlinden J. Alexithymia and dermatology: the state of the art. Int J Dermatol. 2008;47(9):903-10.

10. Turkmen D, Altunisik N, Sener S, Colak C. Evaluation of the effects of COVID-19 pandemic on hair diseases through a web-based questionnaire. Dermatol Ther. 2020.
11. Kutlu Ö, Aktaș H, İmren IG, Metin A. Short-term stress-related increasing cases of alopecia areata during the COVID-19 pandemic. J Dermatol Treat.

12. Garcovich S, Bersani FS, Chiricozzi A, De Simone C. Mass quarantine measures in the time of COVID-19 pandemic: psychosocial implications for chronic skin conditions and a call for qualitative studies. J Eur Acad Dermatol Venereol. 2020.

13. Jafferany M, Franca K. Psychodermatology: basics concepts. Acta Derm Venereol. 2016;96(217):35-7.

14. Bulat V, Situm M, Azdajic MD, Likic R. Potential role of IL-17 blocking agents in the treatment of severe COVID-19? Br J Clin Pharmacol. 2020.

15. Xu Z, Shi L, Wang Y, et al. Pathological findings of COVID-19 associated with acute respiratory distress syndrome. Lancet Respir Med. 2020;8(4):420-422.

16. Ramot Y, Marzani B, Pinto D, Sorbellini E, Rinaldi F. IL-17 inhibition: is it the long-awaited savior for alopecia areata? Arch Dermatol Res. 2018;310(5): 383-90.

17. Bain KA, McDonald E, Moffat F, et al. Alopecia areata is characterized by dysregulation in systemic type 17 and type 2 cytokines, which may contribute to disease-associated psychological morbidity. $\mathrm{Br} \mathrm{J}$ Dermatol. 2020;182(1):130-7.

18. Alexopoulos A, Chrousos GP. Stress-related skin disorders. Rev Endocr Metab Disord. 2016;17(3): 295-304. 